\title{
Tuning the Resonance Frequency and Miniaturization of a Novel Microstrip Bandpass Filter
}

\author{
A. Rezaei ${ }^{\mathrm{a},{ }^{*}}$ and L. Noori ${ }^{\mathrm{b}}$ \\ a Department of Electrical Engineering, Kermanshah University of Technology, Kermanshah, Iran \\ ${ }^{b}$ Young Researchers and Elite Club, Kermanshah Branch, Islamic Azad University, Kermanshah, Iran
}

Received 8 June 2016; Accepted 24 December 2017

\begin{abstract}
In this paper, a compact microstrip bandpass filter is designed using two open loop resonators. In order to obtain a tunable bandpass response with low insertion loss, two stubs are loaded inside them. The design process is based on obtaining the input admittance. Then, using the input admittance, a method is presented to control the resonance frequency and miniaturization simultaneously. The obtained insertion loss and the return loss at the resonance frequency are $0.1 \mathrm{~dB}$ and $19.7 \mathrm{~dB}$ respectively. To verify the design method, the proposed filter is fabricated and measured. The measured results are in good agreement with the simulated results.
\end{abstract}

Keywords: Microstrip filter; Tunable; Miniaturization; Insertion loss.

$$
\text { نطاق ترددي مضغوط باستخدام شريحة جديلة متتاهية الصغير }
$$

الملخص: هُ هذه الورقة البحثية ، تم تصميه مرشح نطاق ترددي مضغوط باستخدام رناناتين ذواتا حلقة مفتوحة . و من أجل الحصدل على استجابة نطاق قابل للضباط ذو بخسارة منخفضة عند الإدراج ، يتم تحميل شريحتين بداخله .وتعتمد عملية

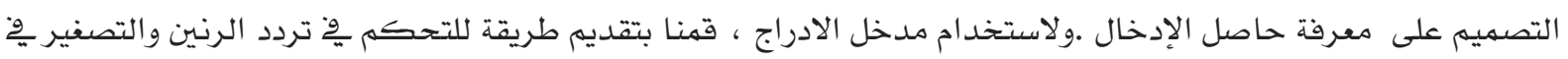

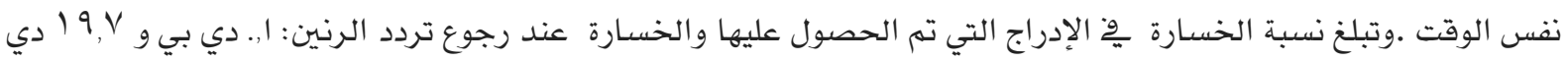
بي على التوالي .وللتحقق من طريقة التصميهم ، يتم تصنيع الفلتر المقترح وقياسـه .و اظهرت نتائج القياس توافقا بشكل جيد مع نتائج المحاكة. الكلمات المفتاحية : مرشتح ، شريحة متتاهية الصغر، قابل للانضباط ، التصغير ، الخسارة وِّ الإدراج

* Corresponding author's e-mail: unrezaei@yahoo.com 


\section{Introduction}

High performance and compact microstrip filters play an important role in developing modern microwave/RF communication circuits and systems. To design microstrip filters several types of resonators such as: open loops (Hayati et. al. 2012; Salehi et. al. 2014; Hayati et. al. 2014; Zhang et. al. 2012), parallel-coupled lines (Moradian et. al. 2009; Othman et. al. 2013; Fathelbab et. al. 2005; Kuan et. al. 2010) and quarter/half wavelength resonators ( $\mathrm{Li}$ et. al. 2010; Deng et. al. 2010) have been used. Also, several approaches on suppressing harmonics have been proposed (Kang et. al. 2010; Wang et. al. 2008; Chen et. al. 2009; Cheng et. al. 2014; Wu et. al. 2017). In Zhang et. al. (2012), three open loop resonators are used to design a bandpass filter with a high selectivity. However, it has an undesired fractional bandwidth. The common weakness of these reported filters is their large sizes and large insertion losses. In Moradian et. al. (2009) a third-order bandpass filter is proposed to attenuate the harmonics. In Kuan et. al. (2010), the parallel coupled lines and step impedance resonators are used to design a microstrip bandpass filter. A microstrip bandpass filter operating at $1.78 \mathrm{GHz}$ with suppressed harmonics up to $6.2 \mathrm{GHz}$ is presented in Li et. al. (2010). But this filter has a large return loss. In Kang et. al. (2010), a ringbalun bandpass filter has been proposed to attenuate the harmonics up to $12 \mathrm{GHz}$. In Wang et. al. (2008), coupled ring resonators have been utilized to design a bandpass filter with a complex structure, while using a complex structure leads to hard fabrication. In Chen et. al. (2009), various types of bandpass filters have been introduced utilizing cross coupled resonators to suppress the second harmonic. Nevertheless, their stop bands are narrow. In Cheng et. al. (2014), the inductive-coupled stepped-impedance quarter-wavelength resonators are used to design a microstrip bandpass filter with an undesired insertion loss. A dualmode microstrip bandpass filter operating at 1.67 GHz has been introduced in Lu et. al. (2017), which has a narrow fractional bandwidth and large area. A microstrip bandpass filter with high return loss has been designed in Guan et. al. (2017). In this filter, a triangular cell has been coupled to the step impedance feed structures that results in improving the bandwidth.

In this paper, first a simple resonator (open loop) is chosen similar to Hayati et. al. (2012); Salehi et. al. (2014); and Hayati et. al. (2014). Then, a method is proposed for miniaturizing and tuning the resonance frequency simultaneously. Using this method, the shapes and dimensions of the internal stubs can be determined as well as the resonance frequency. Next, a simple tunable bandpass filter is presented using two proposed resonators to solve the problems of previous works in terms of large implementation area and large insertion loss. In addition, the harmonics are attenuated reasonably and fractional bandwidth and selectivity are improved. Finally, the effect of changing the dimensions on the frequency response is investigated.

\section{Filter Design}

An open loop resonator is shown in Fig. 1a. A large size simple step impedance cell is loaded inside the proposed resonator to control the resonance frequency. The electrical lengths $\theta_{i}$ are used to obtain the input admittance, where $i=1,2,3$, s. An $L C$ equivalent circuit of the proposed resonator is shown in Fig. $1 b$, where $C$ and $L$ are the capacitors and inductors of the bends respectively. The parameters $C_{g}$ and $C_{p}$ present the gap capacitors. The parameters of $L_{a}, L_{b}, L_{c}, L_{e}, L_{f}$ and $L_{g}$ are the inductors of the stubs with the physical lengths $l_{a}, l_{b}, l_{c}, l_{e}, l_{f}$, and $l_{g}$ respectively. $C_{o}$ is the capacitor of the open end, which its position is subsequent the loaded step. $C_{s}, L_{S 1}$ and $L_{S 2}$ are the capacitance and inductance of the step impedance cell. The input admittance from the open end of $\theta_{1}$ can be written as follows:

$$
Y_{\text {in }}=j Y \frac{\tan \left(\theta_{1}\right)+\tan \left(\theta_{2}\right)+\tan \left(\theta_{3}\right)+\tan \left(\theta_{s}\right)}{1-\tan \left(\theta_{1}\right)\left[\tan \left(\theta_{2}\right)+\tan \left(\theta_{3}\right)+\tan \left(\theta_{s}\right)\right]}
$$

where $\theta_{\mathrm{s}}$ is the total electrical length of the step impedance cell, $Y$ is the admittance of the step impedance cell and open loop resonator. For the even mode, when, $Y_{i n}=0$, the resonance condition is obtained from:

$\tan \left(\theta_{1}\right)+\tan \left(\theta_{2}\right)+\tan \left(\theta_{3}\right)+\tan \left(\theta_{s}\right)=0$

So the resonance condition can be tuned by adjusting $\theta_{1}, \theta_{2}$, and $\theta_{3}$ while $\theta_{s}$ is fixed. The electrical length has a direct relation with the physical length. Therefore, the resonance frequency can be controlled by adjusting the loop and step impedance open stub dimensions. 
When the electrical length $\theta_{s}$ is maximum, then from $\theta_{s}=l_{s} \beta$ (where $\beta$ is propagation constant) $l_{s}$ must be maximum. Therefore, by choosing a maximum value for $l_{s}$, (from Equation 2 and also from $\left.\theta_{s}=l_{s} \beta\right) \tan \left(\theta_{s}\right)$ is increased and the total of $\tan \left(\theta_{1}\right)+\tan \left(\theta_{2}\right)+$ $\tan \left(\theta_{3}\right)$ is decreased $\left(\tan \left(\theta_{1}\right)+\tan \left(\theta_{2}\right)+\tan \left(\theta_{3}\right)\right.$ is minimum). Under this condition $\theta_{1}, \theta_{2}$, and $\theta_{3}$ are small values. Therefore, (from $\theta_{3}=\left(l_{a}+l_{g}+l_{f}\right)$ $\beta, \theta_{2}=l_{c} \beta$ and $\theta_{1}=l_{e} \beta$ ) the open loop dimensions consisting of $l_{a}, l_{b}, l_{c}, l_{e}, l_{f}$, and $l_{g}$ are decreased. This is a method to decrease the resonator size and adjust the resonance frequency simultaneously.

As a total result of above discussion, a method to control the resonance frequency and miniaturization is obtained by the following steps: In the first step, a resonator is selected which some stubs are loaded inside it. In the second step, the main resonator size is decreased and the dimensions of stubs are increased, so that the desired resonance frequency can be obtained. In the proposed resonator (Fig. 1a), the physical lengths $l_{a}, l_{b}, l_{c}$ $l_{e}, l_{g}$ and $l_{f}$ must be smaller while the internal stub length must be larger. Therefore, the inductors $L_{a}, L_{b}, L_{c}, L_{e}, L_{g}$ and $L_{f}$ can be smaller and $L_{S 2}$ or/and $L_{S 1}$ can be larger.

According to Equation (2), in some cases, there is a degree of freedom to control the resonance frequency so that we have to use the optimization method. Therefore, in order to obtain a compact size at the target resonance frequency, the additional optimization is performed.

In order to design a bandpass filter as shown in Fig. 2a, two open loop resonators consisting of different step impedance cells are used. The loops are connected together using mix coupling. The coupling structure consists of three coupled lines with different widths, which are used to attenuate the harmonics. The feed structures with the step impedance forms are added to the input and output ports to decrease the insertion loss without size increment. The simulated and measured frequency responses of the propose filter are shown in Fig. $2 b$. According to the above discussion, the resonance frequency can be controlled by adjusting the physical lengths of open loops while the internal stubs have a maximum size. Therefore, a method to control the resonance frequency is changing of the lengths $\left(\mathrm{L}_{3}, \mathrm{~L}_{9}\right)$ or/and $\left(\mathrm{L}_{4}, \mathrm{~L}_{11}\right)$.

The frequency response as a function of $\mathrm{L}_{3}$, $\mathrm{L}_{9}, \mathrm{~L}_{4}$ and $\mathrm{L}_{11}$ are shown in Fig. $3 \mathrm{a}$ and Fig. 3 b.
Figures $3 \mathrm{a}$ and $3 \mathrm{~b}$ depict the loop size changing effect on the resonance frequency. When the loops are large, the resonance frequency is shifted to the left. When the loops are small, the resonance frequency moves to the right. A photograph of the fabricated filter is shown in Fig. 3c.

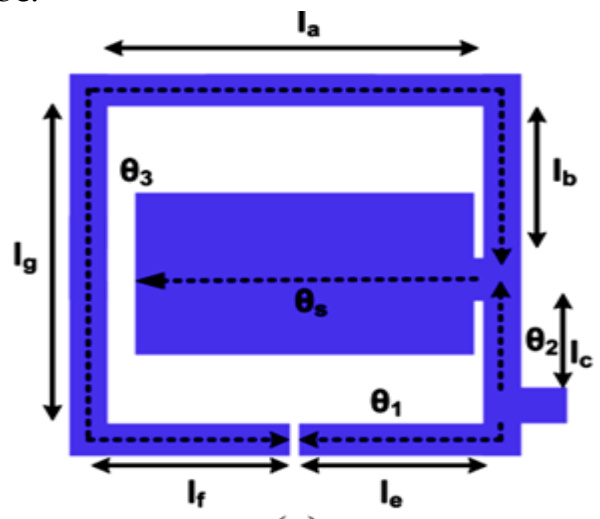

(a)

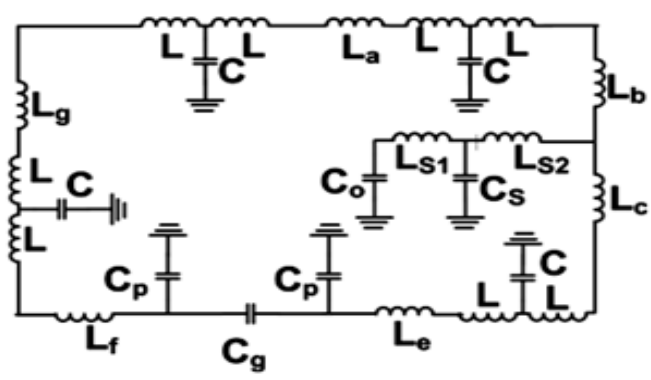

(b)

Figure 1. Proposed resonator (a) layout, (b) LC equivalent circuit.

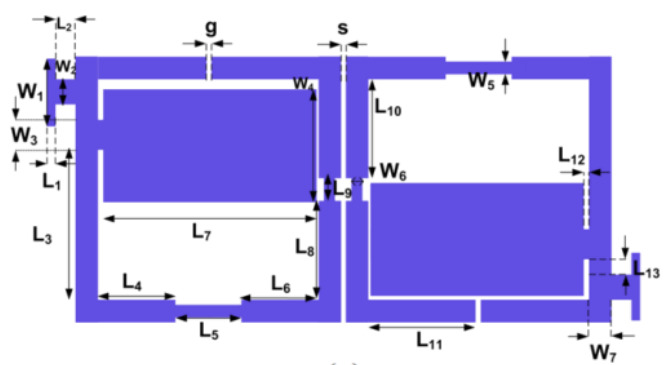

(a)

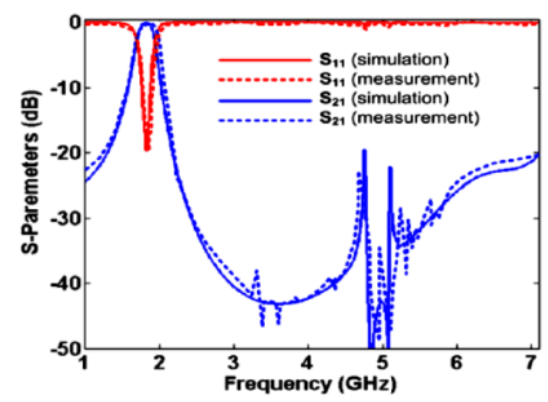

(b)

Figure 2. Proposed filter (a) layout, (b) frequency response. 


\section{Results}

The proposed filter is simulated by Advanced Design System (ADS) full wave EM simulator. The proposed filter is designed and fabricated on a RT_Duroid_5880 substrate with 15 mildielectric thickness, $\varepsilon_{\mathrm{r}}=2.22$ and loss tangent 0.0009. The dimensions of the proposed structure shown in Fig. $2 \mathrm{a}$ are presented in Table 1. This filter has the cutoff frequencies at $1.68 \mathrm{GHz}, 1.93 \mathrm{GHz}$ and the resonance frequency is $1.8 \mathrm{GHz}$. The harmonics are attenuated from 2.16 up to $7.1 \mathrm{GHz}$ with a maximum level of $19.5 \mathrm{~dB}$. Therefore, the harmonics are attenuated up to $3.94 f_{o}$ where $f_{o}$ is the resonance frequency. The obtained insertion loss at $1.8 \mathrm{GHz}$ is better than $0.1 \mathrm{~dB}$, while the return loss is better than $19.7 \mathrm{~dB}$. The filter size is $0.23 \lambda_{\mathrm{g}} \times 0.1 \lambda_{\mathrm{g}}$ $\left(26.7 \times 12 \mathrm{~mm}^{2}\right)$. In comparison to the previous works, the filter size is small and the best insertion loss is obtained. The achieved fractional bandwidth (FBW) is $14 \%$. The insertion loss, return loss, fractional bandwidth, and filter size are compared to the previous works in Table 2. In the Table 2, IL, RL, and FBW are the insertion loss, return loss, and fractional bandwidth respectively.

\section{Conclusion}

A simple compact low loss bandpass filter is designed, fabricated and measured for RF systems. In this structure, two open loop resonators are loaded by two large stubs. By using the additional large size microstrip cells inside the open loops, the resonance frequency is decreased without size increment. The overall size of the proposed filter is $320 \mathrm{~mm}^{2}$. In comparison to all of the references, the lowest

Table 1. The dimensions of proposed structure (in $\mathrm{mm}$ ).

\begin{tabular}{ccccccccc}
\hline Parameters & $\mathbf{L}_{1}$ & $\mathbf{L}_{2}$ & $\mathbf{L}_{3}$ & $\mathbf{L}_{4}$ & $\mathbf{L}_{5}$ & $\mathbf{L}_{6}$ & $\mathbf{L}_{7}$ & $\mathbf{L}_{8}$ \\
\hline Value & 0.3 & 1 & 6.8 & 3.5 & 3 & 3.5 & 9.7 & 4.5 \\
Parameters & $\mathrm{L}_{9}$ & $\mathrm{~L}_{10}$ & $\mathrm{~L}_{11}$ & $\mathrm{~L}_{12}$ & $\mathrm{~L}_{13}$ & $\mathrm{~W}_{1}$ & $\mathrm{~W}_{2}$ & $\mathrm{~W}_{3}$ \\
Value & 1 & 4.5 & 4.8 & 0.2 & 1 & 3 & 1.2 & 1 \\
Parameters & $\mathrm{W}_{4}$ & $\mathrm{~W}_{5}$ & $\mathrm{~W}_{6}$ & $\mathrm{~W}_{7}$ & $\mathrm{~S}$ & $\mathrm{~g}$ & & \\
Value & 5 & 0.6 & 0.5 & 1 & 0.1 & 0.4 & & \\
\hline
\end{tabular}

Table 2. Comparison between the proposed filter and previous works.

\begin{tabular}{cccccc}
\hline Reference & IL $\mathbf{( d B})$ & RL $\mathbf{( d B})$ & FBW & Size $\left.\mathbf{( m m}^{\mathbf{2}}\right)$ & $\mathbf{f}_{\mathbf{o}}(\mathbf{G H z})$ \\
\hline This work & 0.1 & 19.7 & $14 \%$ & 320 & 1.8 \\
(Hayati et. al. 2012) & $0.53,0.59$ & $10,13.4$ & --- & 320 & $2.4,5.2$ \\
(Salehi et. al. 2014) & $0.35,0.25$ & $13.6,18.2$ & $17 \%, 13 \%$ & 363 & $2.4,5.7$ \\
(Hayati et. al. 2014) & $0.2,0.4$ & $15,12.7$ & $13 \%, 11 \%$ & 233 & $2.4,5.2$ \\
(Zhang et. al. 2012) & 2.2 & --- & $6 \%$ & 11595 & 0.95 \\
(Moradian et.al. 2009) & 3.85 & --- & $13 \%$ & 9000 & 1 \\
(Kuan et.al. 2010) & 2.5 & 15 & $12 \%$ & 2034 & 2 \\
(Li et.al. 2010) & 1.8 & 12 & $16.5 \%$ & 488 & 1.78 \\
(Deng et.al. 2010) & 1.66 & --- & $9.5 \%$ & 606 & 2.41 \\
(Kang et.al. 2010) & 1.34 & 21.6 & $4.08 \%$ & 1564 & 2.45 \\
(Chen et.al. 2009) & 0.83 & --- & 11.2 & 2300 & 2 \\
(Cheng et.al. 2014) & 0.85 & --- & $11.5 \%$ & 220 & 2.35 \\
\hline
\end{tabular}



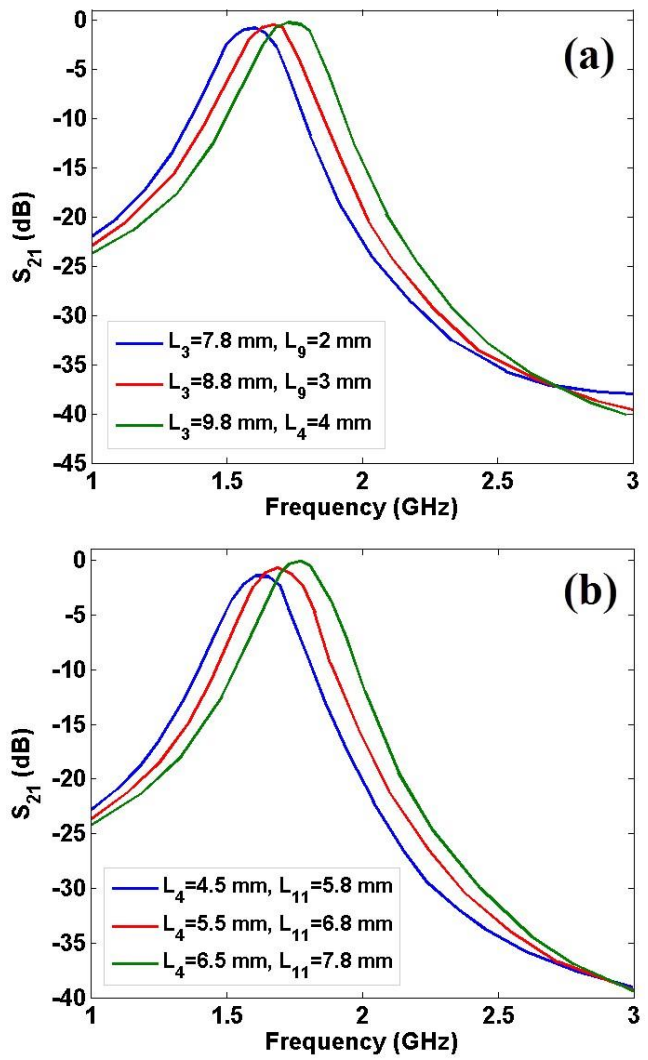

(c)

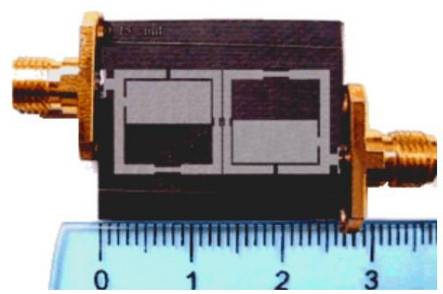

Figure 3. (a) Frequency response as a function of $\mathrm{L}_{3}$ and $\mathrm{L}_{9},(\mathrm{~b})$ Frequency response as a function of $\mathrm{L}_{4}$ and $\mathrm{L}_{11}$, (c) a photograph of the fabricated filter.

insertion loss is obtained, while the harmonics are attenuated from 2.16 to $7.1 \mathrm{GHz}$ with a maximum attenuation level of $-19.5 \mathrm{~dB}$. In addition, the resonance frequency is tuned by calculation of the input admittance

\section{Conflict of Interest}

The authors declare no conflicts of interest.

\section{Funding}

No funding was received for this research.

\section{References}

Chen WL, Wang GM (2009), Effective design of novel compact fractal-shaped microstrip coupled-line bandpass filters for suppression of the second harmonic. IEEE Microwave and Wireless Components Letters 19(25): 74-76.

Deng PH, Chiu PT (2010), New bandpass filters using half-wavelength and branch-line resonators. Progress In Electromagnetics Research, 16: 241-249.

Fathelbab WM, Steer MB (2005), Parallelcoupled line filters with enhanced stopband performances. IEEE Transactions on Microwave Theory and Techniques 53(12): 3774-3781.

Guan X, Gui P, Xiong T, Ren B, Zhu L (2017), Hybrid microstrip/slotline ultra-wideband bandpass filter with a controllable notch band. International Journal of Antennas and Propagation 2017: 1-7.

Li YC, Zhang XY, Xue Q (2010), Bandpass filter using discriminating coupling for extended out-of-band suppression. IEEE Microwave and Wireless Components Letters 20 (7): 369-371.

Moradian M, Tayarani M (2009), Improving the stopband of microstrip parallel-coupled line bandpass filters using partially coupled resonators. IET Microwaves, Antennas and Propagation 4(7): 906-916.

Othman MA, Sinnappa M, Hussain MN, Abd MZA, Ismail MM (2013), Development of 5.8 $\mathrm{GHz}$ microstrip parallel coupled line bandpass filter for wireless communication system. International Journal of Engineering and Technology 5(4): 3227-3235.

Salehi MR, Abiri E, Noori L (2014), Design of a microstrip dual-band bandpass filter with compact size and tunable resonance frequency for WLAN application. International Journal of Electronics Communication and Computer Engineering 6(3): 248-251.

Wang Y, Wang BZ, Wang J (2008), The design of coupled resonator bandpass filter with wide stop-band. IEEE Microwave and Wireless Components Letters 18(4): 251-253.

Wu XH, Wei XB, Lv HG, Shi Y (2017), A compact trisection microstrip bandpass filter with frequency-dependent cross-coupling. Electromagnetics 37(7): 454-461.

Zhang XY, Xue Q (2009), Harmonic-suppressed bandpass filter based on discriminating coupling. IEEE Microwave and Wireless Components Letters 19(11): 695-697. 